\title{
Designing Accountability: the Managerial Semiotics Project.
}

by

\section{Peter Armstrong}

Acknowledgement: This paper was written in the course of a research project directed by Anne Tomes and sponsored by the UK Design Council on the use of product market information in design decisions. The arguments and conclusions presented in the paper, however, are entirely the author's own. 


\begin{abstract}
The empirical occasion of this paper is an experiment by the Sharp electronics company in the application of semiotics to the management of aesthetic design. On the assumption that the visual 'signs' incorporated into products are freely translatable to and from linguistic messages, a verbal-visual 'dictionary of translation' was built up from designers' own accounts of the reasons behind their design decisions. The aim was to construct a form of accountability for design so as to render it transparent to managerial control.

This exercise is viewed as an example of the continuing pressure upon management science ('consumer behaviour' in this instance) to produce languages of accountability through which expertise can be made to report to the inexpert. It is suggested that the market for such languages of accountability is rooted in virtual universality of the 'task-discontinuous status organisation' Offe (1976). Organisations of this kind are characterised by horizontal discontinuities at which the hierarchy of expertise gives way to one of managerial technology. It is these which pose the problem of agency to which languages of accountability appear as an answer.

The problem is that such languages are constrained by their market to represent expert practice as intelligible to, and controllable by, a stratum of general managers. Where this is not the case, as is arguably so with aesthetic design, attempts to control practice on the basis of a misleading picture of that practice are likely to result in dysfunctionalities. In the case of the Sharp experiment the outcome was a naive attempt to convey a complex textual message through the choice of a colour for one of the company's products.

The paper then discusses the alternative of allowing languages of accountability to emerge from the culture of practice itself. The problem here is that the resulting forms of accountability are likely to allow generous space for professional self-interest. A third possibility is then indicated: that of negotiating forms of accountability between practitioner and user on the model of community participation in architectural design.
\end{abstract}

Keywords: Accountability, Managerialism, Control, Design, Semiotics, Participation. 


\section{Introduction}

\subsection{Discursive Accountability and Managerialism}

The critique of what Humphrey, Miller and Scapens (1993) have called 'accountable management' has gathered considerable momentum in recent years (e.g. Cochrane, 1993; Gray and Jenkins, 1993; Ezzamel and Willmott, 1993; Laughlin, Broadbent and Willing-Atherton, 1994; Lawrence, Manzurul and Lowe, 1994: Chua and Preston, 1994; Ogden, 1995). Particularly in the public sector services, simplified accounting indices of performance are proving inadequate as surrogates for outputs which are concrete, complex and politically-contested. Similar issues have arisen in the private sector, where wider forms of accountability are being debated under the headings of green and social accounting (e.g. Gray, Owen and Maunders, 1987; Owen (ed.), 1992; Gray, 1993; Gray, Owen and Adams, 1996). Even where the accepted priority is capital accumulation, an over-reliance on accounting controls is now routinely excoriated as 'management by the numbers' (Chandler, 1977, p. 480, Johnson and Kaplan, 1987). For these reasons, amongst others, there has been a recent shift in the terms of debate, from accounting, narrowly conceived, to the broader notion of accountability (Munro and Mauritsen, 1996).

This shift has, in turn, stimulated critical thinking about the notion of accountability itself. In a notable contribution, Roberts $(1991,1996)$ has pointed out that conventional hierarchical forms of accountability tend to dislocate the responsibility for individual action from the matrix of its antecedents and consequences. As a result, these 'individualising' forms of accountability also divorce moral from technical responsibility. The prospects for a re-integration of the two, argues Roberts, depend upon the development of 'horizontal' relationships of mutual accountability. These 'socialising' forms of accountability offer the space for a dialogue between mutually accountable colleagues which may accommodate moral judgements as well as appraisals of technical efficiency.

Roberts' schema has been criticised by Boland and Schultze (1996) for too close an identification of hierarchical with individualising accountability. What matters, they say, is the mode of cognition involved, not the organisational taxonomy. The true connection, they argue, lies between individualising accountability and a 'paradigmatic' form of cognition, which grasps reality through concepts which are manipulated according to relatively stable rules of thought. The enabling condition of socialising accountability is that it takes place through the medium of a 'narrative' mode of cognition, which grasps reality through story-telling populated with actors in meaningful situations.

Substantively speaking, this critique rests on a belief that organisational hierarchy need be no obstacle to genuine dialogue. That is, superiors and subordinates can freely exchange moral concerns irrespective of the control of the life chances of the one by the other. This is possible, of course, but the experience of many whistleblowers, and of the much larger number who have swallowed their moral concerns for the sake of the quiet life, indicates that Roberts is more often right than wrong.

In fact Roberts' prescription for a re-integration of moral and technical accountability could itself be accused of over-sanguinity. Notwithstanding the ethical possibilities of horizontal forms of accountability, it seems clear that these can only ever be 
established within communities of collective self-regulation ${ }^{1}$. Outside of these enclaves, the core institutions of the capitalist economy are not easily going to be delivered over to collegiate control. It follows that hierarchical accountability is going to remain the general rule and that the 'traditional' question of its ability to monitor the performance of complex tasks remains on the agenda.

This paper relates to the work of Roberts $(1991,1996)$ and Boland and Schultze (1996) in that it is also concerned with the language of accountability. For the reasons given above, however, it is hierarchical accountability which is in question, and its ability to monitor complex tasks rather than distribute moral responsibilities. The basic argument is that even discursive languages of accountability are likely involve the imposition of vocabularies of motive which distort the practices accounted for. This tendency, it will be argued, is structurally located in the 'task-discontinuous status organisation' (Offe (1976) which is virtually universal in late $20^{\text {th }}$ century capitalism. Organisations of this kind are characterised by horizontal sutures at which the hierarchy of operational expertise gives way to one of managerial technology. These discontinuities which pose the problem of agency to which the languages of accountability - discursive, as well as numeric - appear as solutions: that of how expertise can be controlled by those who lack it (Armstrong, 1991). The form of the question, it will be argued, largely determines the form of the answer. Discourses of accountability will represent the outputs of expertise as intelligible to, reflecting the values of, and amenable to control by, the managers of the task - discontinuous status organisation. To the extent that these languages distort the practices accounted for (from the practitioner viewpoint), the capture of discursive accountability by the managerialist project is likely to involve much the same kind of dysfunctionalities as accounting numbers.

An interesting recent paper by Oakes (1996) can be viewed as exploring a possible way forward. This describes the accounts given by a 19th Century charitable mission in Chicago. Consisting of reports and diaries, these accounts were distinguished, not only by their discursive medium, but by the fact that they were offered in a form and language spontaneously decided by the organisers of the mission, and directed towards the supporting public rather than a stratum of general managers. As a solution to the agency problem, the interest of this form of accountability is that it recognises that information asymmetry extends to the question of the content of accounts, as well as the concrete situation behind the reports. Expert practitioners - or simply those who are on the spot - possess knowledge relevant to the question of what they should be accountable for, as well as the concrete details of the situation for which they are accountable. As a solution to the problem of accountability, this raises issues which will be explored in the concluding remarks. The central object of the present paper, meanwhile is to demonstrate that the validity of such an approach depends crucially on genuine practitioner input into the language of accountability. If it is the product of 'consultation' or 'participation' offered by a stratum of general managers, this is likely to be on terms which will infiltrate their own priorities into the resulting system of accountability.

\footnotetext{
1 This limitation on the scope for horizontal accountability raises the important question of where its boundaries are to be drawn. If, for example these coincide with a community of professional practitioners and exclude the public on which their art is practised, the result will be an imposition of the ethics - and the interests - of the profession.
} 
This was the case with an experiment in the managerial control of aesthetic design described in the body of the paper. For managerialism, this may be the last great frontier. It is here that materialistic entrepreneurialism on the one hand, and the rational planning of the corporation on the other confront the creative mysteries of romantic individualism. The particular case to be examined is that of an attempt to manage product aesthetics through a version of applied semiotics. The intention was to create a 'dictionary' of translation between the kind of discursive meanings which managers would like their customers to absorb and the visual forms created by designers. Besides being at odds with most authoritative treatments of visual semiotics, this 'assumption of translatability' does considerable violence to designers' own conceptions of the manner in which design works and is achieved. The consequence in this particular case is that managers were led to invest in a form of behavioural science which was based on the premise that complex textual messages to potential consumers can be conveyed by the choice of a product's colour.

It will be argued that this experiment was based on an interpretation of semiotics distorted by the market for technologies of management created by the prevalence of the task-discontinuous status organisation. In such organisations, the problem of managing product aesthetics is that of how designers who live in a visual and tactile world can be made accountable to managers who do not. This requires that design be translatable, not just into ordinary language, but into a language of consumer valencies. That the weight of authoritative opinion in semiotics is inclined against these assumptions cannot be allowed to stand in the way. A managerially useful semiotics must assume translatability, and so it does assume translatability. The outcome is likely to be designs which can be justified at all points in ordinary language, and against a marketing plan: the certainties of dullness.

\subsection{Design, Competition and Control}

In the management of product aesthetics, the stakes are potentially high, especially in fields of competition characterised by stable technologies. Where this is the case, product differentiation by functional performance is difficult to achieve, so that look and feel become important ways of creating competitive advantage. This is Art Blakesee, head of Citröen's Design Centre:

We have arrived at the point where all cars are at the same level of finish and attention to detail. The question now is who has the creative design staff who can make the next big jump. The market is ready for big changes.

Quoted in Copps (1995)

Other examples occur in the field of consumer electronics (Hoshino, 1987). At the level of individual products:

The X-factor in the product is its essential personality, its desirability quotient, if you like - those intangible, emotional features, over and above function and efficiency, that make one product better and more desirable than another. It's the first thing that strikes you and it often makes itself felt in an immeasurable fraction of a second. It's the "I like it, I want it, what is it?" element in a product. We're constantly searching for that elusive iconography, the psychological bridge between consumers as they are and consumers as they'd like to be

Seymour, R. in Seymour Powell (n.d.) 
To designers, the ingredients of design-based competition are a creativity empathy with the lifestyle-conscious consumer, a sense of what will connect with the subrational impulse to acquire, and the flair and originality to lock onto these openings in ways which leave the competition flat-footed:

The designer is a radar-scanner, probing art, architecture, technology, fashion, the market-place, pop music, everywhere. Plenty of people, such as marketing consultancies, can build a bedrock of predictive information, but they can't make the creative, sideways jump. We move on to the next stage and translate that data into design.

Powell, R. in Seymour Powell (n.d.) p. 114

Ranged against this practitioner insistence on the elusive, not to say fragile, character of creative design, there is a weighty, if somewhat plodding, literature on design management (see Craig and Hart, 1994, for a review). Though concerned with design for functionality as much as product aesthetics, the emphasis here is on planning, on researching consumer's needs and on ensuring that these are fed into the design process. The thrust is towards managing design so as to guarantee that it will deliver its promised competitive advantages. Design is viewed as something which can easily get out of hand.

From the management point of view, there may be something in this. According to one prominent consultant designer (Thompson, 1995), few product designers would take market success into account if asked to nominate examples of good design. Given the commitments involved in the introduction of new products, this kind of irresponsibility needs to be held in check.

The apparently rational answer, rehearsed at length by researchers on new product development (NPD), is to infiltrate market research into the design process (e.g. Moenaert et al,1994). The fundamental problem with this prescription is that capitalism is not a rational system of production; it is a competitive system. If all of the firms within a certain market perform competent market research and ensure that their designers incorporate its findings into their products, the logical consequence will be that all of the products will fit the market. The end result will be a convergence of design which confers no competitive advantage on anyone. According to Lorenz (1986), exactly this occurred with the 1970s fashion for 'consumer clinics' in the motor industry. In these clinics, representative punters were invited to evaluate proposed new design features against those of competing products. The idea was to steal a march on the competition by combining the best. The result was a regression towards an aesthetic norm which then stagnated. As has previously been argued by Armstrong and Tomes (1996), there is a contradiction lurking within the idea that a competitive advantage based on creativity and surprise can be guaranteed through rational planning.

However unfortunate they may be for the management of the corporation, contradictions of this kind are fertile ground for the fads and foibles of management science. Like cellulite and the common cold, the problems are real, persistent and incurable, all of which make for dynamism in a market for cures. The product on view in the present paper is called semiotics, the study of signs. In its modern form, semiotics derives from the linguistics of Saussure and the analytics of Peirce. The literature, much of which is concerned with linguistic signs, is very extensive. So far, 
however, it is mostly the semiotics of the visual sign which has been imported into consumer research by entrepreneurial management scientists (e.g. Mick, 1986). The promise is that an understanding of the sign -properties of physical form will lead to a technology through which products can be designed so as to convey predetermined 'messages' to the consumers. Thus design, like other labour processes could be subjected to detailed rather than general managerial control and the dependence of corporate design strategy on the eccentricities and tantrums of the 'creatives' would be diminished.

\section{Managerial Semiotics and the Control of Product Design}

Before semiotics could become an instrument of marketing, it had, itself to be marketed. The sales pitch was spelt out at the First International Conference on Marketing and Semiotics at North Western University: 'Consumers are practising semioticians with a considerable expertise in reading and manipulating the meanings circulating in their society . . ' (Umiker-Sebeok, 1987). From this, it followed that marketing managers too, were in the business of semiotics, whether they realised it or not.

The indispensable first move in the production of a manageable semiotics of the product is to assume that the visual and tactile languages of design are really approximate ways of communication verbally-defined feeling states. Only on this basis can the 'signs' projected by products and advertising be rendered amenable to academic discussion and accountable to corporate management. A previous discussion of this issue (Armstrong and Tomes, 1996), described an approach by Bruce and Burrill (1995) in which (verbal) interviews with designers were used to establish the (linguistic) meanings which they believed that their designs had communicated. Once designers have been manoeuvred into making claims of this kind, they become auditable using the ordinary techniques of market research. Representative consumers can be asked to report on the extent to which they have received the 'intended' verbal meanings, and the results used to construct a numerical index of design effectiveness. The process is analogous in some respects to the use of consumer opinion polls to create indices of performance in the public services (Cochrane, 1993).

In the foregoing instance, the control of design takes the form of a post-completion audit. The process itself remains a black box and the professional expertise of the designer remains intact. Once design has been reduced to an encryption of the verbal, however, it becomes possible to intrude managerial decision-making into the process itself. The mechanism here is to use designers' own (verbal) accounts of the reasoning behind certain design features to set up an expert system which is essentially a verbal - visual 'dictionary'. This can then be used either to evaluate future designs, or to translate managerial decisions on the verbal meanings to be incorporated into products directly into design features. This was the approach of a self-styled exercise in semiotics by Kawama (1987) carried out for the Sharp electronics corporation of Japan.

Kawama's research is examined in detail here, not because he is an important figure in the study of semiotics or design management, but because it offers an unusual sighting of the managerialist project in its natural setting: the search for control of the few remaining areas of uncertainty within the giant corporation. The aim of the research was to 'systematise' the designer's choice of product colours in order to 
control the image of the corporation as expressed in its products. Kawama defined the objectives of his research (and of the system of management control based upon it) in the following terms: 'Designers ordinarily decide the colours of products using their own artistic intuition and experience. It is therefore the task of the researcher to convert these intuitions and experiences - a proverbial "blackbox" - into a glassbox in order to develop a "Color Planning System."' Kawama was explicitly aware that this enterprise depended on the assumption that design is essentially a means of communicating a verbal message: 'I began by conceiving of the designer as a translator who converts words into colors for the products.' (Kawama, 1987, p. 66)

In essence, the system was based on designers' own accounts of the reasons behind their colour choices. An initial analysis of the words which they used to describe the colours of products indicated that these were of three kinds: images from nature, words denoting feelings and words associating colours with particular products. The associations between these words, as they were used by the designers, were established by a cluster analysis of questionnaire data. By these means 414 combinations of words used to describe the colours of products were identified. These were then fed back to the designers alongside a colour chart in order to establish the colours associated with each of the word combinations. The resulting 'Color Image Map' - essentially a dictionary of translation between words and colours - has been used to choose the most appropriate colours for Sharp's products.

Kawama offered three caveats: 1) There was some doubt as to how far the colours of products could be accurately represented by words alone. 2) Despite the use of cluster analysis, it was difficult to detect clear patterns in the choice of colours. 3) The method assumed a stable relationship between words and colours whereas in practice this relationship proved to be changeable. Although each one of these difficulties was quite fundamental to the entire exercise, it still went ahead. I will comment later on the pressures which lead to this kind of intellectual march into quicksand.

Some idea of the complexity of the feeling-states supposedly encoded in the colours of Sharp's products can be gleaned by Hoshino's (1987) complementary description of the development of a product concept for a word-processor. Using the 'abductive methods of semiotics', the 'signs' corresponding to the target individuals (young executives) were collected from printed media. The meanings of these were then interpreted to yield a number of key words descriptive of the 'physical needs' of this paradigmatic individual. These included:

High quality, high prestige, independent of fashion, authentic, organic, systematic, advanced functionality, enhanced professionalism, time saving to accommodate enormous demands on the neo-executive.

Similarly for psychological needs:

Highbrow individuality, creation of a new tradition, intellectual elitism, androgynous sense of beauty, mental ecstasy, interest in the inner world.

All of these key words were then wrapped up in two 'meta-signs': 'Intelligent weapon for a mature man', and 'stage-setting for dramatic self-presentation', and these were the messages to be read into the Color Image Map. In this manner what were essentially managerial decisions on the textual messages to be conveyed by the word processor were supposedly translated into a design decision on its colour. 


\section{Design as Refracted Through Accounts of Design}

The notion that the kind of verbal minestrone generated by Sharp's adventure in semiotics could possibly be conveyed simply by the choice of a colour is, of course, absurd. The interesting question is why intelligent people pressed ahead as if blind to the absurdity. I suggest that it stems from two basic is misconceptions, both consequent upon misreading designers' accounts of design for the activity itself. The first is the assumption that design works by aggregating independent units of meaning. I will call this the assumption of molecularity. The second is that it communicates the same kind of message as text. I will call this the assumption of translatability. These assumptions will be considered separately.

\subsection{Design as a Semiotic Aggregate.}

Designers themselves sometimes speak as if particular elements of design convey context-independent meanings. For example, in a recent UK television programme on motor car design one designer spoke of the unbroken bonnet - windscreen line of multi-seat vehicles as signalling (expensive and sophisticated) 'people-carrier', rather than (cheap and nasty) 'van' (Channel 4, 1995). Similarly, in a seminar attended by the author, the designer of an electric kettle added an internal plastic brace with a pattern of holes supposedly evocative of boiling water. The idea, as he put it, was 'to add a bit of product semantics' (Thompson, 1995). The fact that identifiable signs can be described as working in this manner within an overall design, however, does not warrant a leap to the conclusion that effective design can be achieved simply by assembling off-the-shelf semantic units. The context in these instances may be tacit, but it is everything.

As an example, consider Seymour Powell's description of their 'Scorpion' motorcycle designed for former East German manufacturers MZ:

The lean, athletic-looking machine - poised with its tail in the air, with the tips of its "claws" on the ground - possesses much of the animal grace of the insect after which it's named. The twin headlamp unit with its two baleful, almost malevolent, "eyes" reinforces the metaphor perfectly.

Seymour Powell, n.d.

Clearly the visual elements of the design draw their meaning from the whole to which they contribute - a whole, incidentally, which is 'anchored' (c.f. Barthes, 1977) by the name of the product. Though this is an example chosen for its describability in ordinary language, its coherence of composition is characteristic of all competent design. This means that any textually -equivalent message communicated by the colour of Sharp's word processor will depend on the fact that it is a word processor, and one of a particular form and texture. The search for a context-independent meaning for colours is futile in principle. The black of an oil-slick, for example, differs from that of a well-fed cat and differs again from that of the Northrop B2 Stealth Bomber. This, in fact, appears to have been evident in the designers' descriptions of colours from which Kawama's research began (page 8). In using references to products and to nature, the designers may have been trying to convey to the researcher the context -sensitive nature of the meaning of colour. 


\subsection{Design as the Translation of Text.}

As with the assumption of molecularity, designers often speak of design as communication in terms which encourage the idea that what it communicates is defined in the first instance by the verbal. The following extract is from a publicity brochure produced by a graphic design agency:

Very loosely graphic design consists of concept and expression. Theoretically these are two distinct stages in the design process: first you sit down and come up with a single pin-sharp concept that perfectly embodies the essence of whatever it is you want to communicate; then you search for the best way to express it, using colour, type, photography or any of the many other tools of our trade.

Chase, 1993, p. 8.

Such accounts of design, however, need to be understood as exercises in salesmanship as well as explanation. As such, they are directed at a managerial culture whose preferred medium is the imperative sentence. They are, in other words, translations of design intended to represent it as a rational activity as rationality is understood in a materialistic and non-visual culture. That designers themselves feel somewhat out of place in such a culture is evidenced by the following exchange observed by the author in recent fieldwork. A consulting designer is speaking to a product manager in the client company:

Senior Designer: When you lot have a presentation, it's all verbal, isn't it. You stand there with nothing really, just talk about the product, how you got from a to b. I find that incredible, really, that someone has to stand there in a room in front of 30 people and just and talk and talk and communicate that way. For us, it's so different, because we just do it visually and we don't really have to speak an awful lot. Our work speaks for us. It's visual, it's definitely a visual thing, so even when you're presenting to a client you don't have to prepare yourself as to what you're going to say too much because a lot of it is visual. It's a totally different way of presenting. For designers, if you have to go and give a lecture, it's horrendous, it can be frightening. You don't work like that.

When designers try to explain the manner in which design communicates, as opposed to its supposed ability to convey a textual message, they speak in quite different terms. The following examples are from the broadcasts on motor car design referred to on page 9:

... we perceive things we deal with by our senses. I have a great reservoir of subconscious experience and associations .. and .. I believe it is very important that .. a car communicates positively to the subconscious ... and we based it upon the five senses ... one of the important ones obviously is seeing. The car has to look all right, sound very important ... Obviously smell is a very important part. . . the smell of a car interior, for instance, is a subconsciously registered element of quality...

Uwe Bahnsen - Vice President of Design, Ford Motor Company, 1976-1986

Auto-Erotic. Channel 4 Broadcast (Programme 2: The Family Car) 
Physical design, evidently, communicates sensations which are to be experienced in their own terms, not as mere grist to the mill of ordinary language and rational discourse. What is conveyed is a sensual experience.

If it's well done like it is on this car, you get wonderful flowing lines. Something that really tells you something about the passion of the people that modelled it.

Peter Stevens: Consultant Automotive Designer

Auto-Erotic. Channel 4 Broadcast (Programme 1: The Sports Car)

Whilst it is not impossible to attempt descriptions of such feelings in ordinary language, these are likely to be heavily dependent on metaphor, and, even where this is understood as intended, to be very approximate and partial (c.f. Barthes, 1985). The description, in other words, is decidedly not the experience. Seen in this light, the attempt to construct a database of the 'meanings' of design on the basis of designers' descriptions of these meanings can be seen to be flawed in its conception.

\section{The Market for a Managerially Useful Semiotics}

\subsection{Semiotics as a Management Tool: marketability vs. realism}

Now all this has been extensively debated within the field of semiotics, and it would be easy to dismiss the positivistically deformed version taken into consumer research as the product of nothing more than ignorance and folly. In this section of the paper, however, I would like to suggest that it is something more. Amongst the contradictory pressures on managerial science in capitalist society is one between realism and marketability. On the one hand the outputs of management research need to be 'true' in the sense that they do not obviously self-destruct on encounters with the empirical. On the other hand management science is, itself, a marketed product.

This marketability aspect demands, amongst other things, that human practice must be represented as amenable to managerial intervention. The sponsors of management research, after all, are not likely to be happy with the message that the best thing they can do is nothing. Managers, no less than management scientists, need to justify their existence. On the other hand, both practicality and the requirement that knowledge must survive the academic bear-pit, dictate that the consequences of applying management science must not contradict the rationale behind its application. Although there is considerable scope for re-apportioning the blame for disasters and embarrassments, managers like to think of themselves as practical people and their patience is limited. In short, management science must 1) convey the impression that something can be done, and 2) work.

Crucially it is quite possible for these pressures to conflict. There are descriptions of human activity which can be supported by research and which do not imply that there is scope for managerial direction. A familiar example is that of autonomously motivated task performance. Where this exists, a role for management may be rediscovered, albeit at some cost in empirical adequacy, by the redescription of management as facilitation or of the worker as lacking the larger vision, emotionally impoverished, or whatever. The analysis presented in this paper suggests that that this is the case with the managerial version of semiotics described above. The representation of design as amenable to managerial control has been achieved only by 
misrepresenting the workings of design to such an extent that it negates the rationale for investing in it in the first place.

Specifically, the assumptions of molecularity and translatability are attractive in the market for bright ideas about how managers might control things. They posses the marketing advantage of representing design as intelligible and tractable, since ordinary language is both the medium and the output of managerial committees. If there is a one-to-one correspondence between the account of the activity to be controlled (the message to be conveyed by an element of design) and the activity itself (the choice of an element of design), it becomes possible to control the second by controlling the first.

Given this design specification for a managerially useful semiotics of the product, how does academic thinking and research stand up? The question is complicated by the fact that there are two rather different traditions to consider: an interpretative qualitative approach with close links to art criticism and cultural studies, and a positivist - quantitative approach based on the methods of experimental psychology (Holbrook, 1987) ${ }^{2}$. To anticipate the conclusions of the next two sections of the paper, neither tradition provides a warrant for the assumptions of translatability and molecularity.

\subsection{Translatability and molecularity: the view from interpretative semiotics}

Within interpretative semiotics the position most opposed to the assumptions of translatability and molecularity is probably that of Langer (1985). In Langer's view, what is presented to the mind is already selected by the senses. The act of perception itself, therefore, creates abstractions and these are capable of articulation one with another (the notes of a musical scale are an example given by Benveniste, 1985). On this basis there arises the possibility of sign systems in which one abstracted perception can refer to, or stand for, another without ever intersecting with other perceptually-based systems of signification, or with ordinary language (fragmentary or distorted motifs in music might be an example). More, the elements in such nonlinguistic systems can be apprehended only through the meaning of the whole (The notes of a musical theme have meaning only in relation to each other. Langer's own example is the areas of light and shade in a photograph). These elements do not, like the morphemes of language posses an intrinsic generality which can be assembled into a whole within a discourse. The elements of non-linguistic sign systems are not 'words.' There follow two conclusions which are profoundly discouraging for those interested in enrolling semiotics as an instrument of design management: 1) There can be no dictionary of translation between visual experience and ordinary language and 2) Visually-based semiotic systems are not made up of context-independent units of meaning.

Benveniste (1985), in his discussion of the plastic arts, echoes Langer's view of their non-molecularity, but is more flexible on the question of translatability. Colours, he argues, can be assigned to a scale and given names. They do not, however, signify, in the sense of referring to something beyond colour. It is only in relation to a

\footnotetext{
${ }^{2}$ Holbrook calls the interpretative approach 'semiology', reserving the term 'semiotics' for the positivist approach. This terminology is notuniversal, however, and it has not been adopted in the main text.
} 
composition that they assume this kind of signification. It follows that the artist conveys meaning through a composition, rather than through a combination of elements which have an initial meaning in isolation.

On the question of translatability, Benveniste starts from the position that language is the master interpretative system of society. On that basis he believes that it is capable (eventually!) of interpreting signs in non-linguistic media. For the critic, the fortunate implication is that writing on art, music or football is possible. Equally fortunately for the artist, perhaps, the reverse relationship does not hold. A picture may be discussed in a thousand words, but it cannot be made to signify a thousand word discussion.

The discussions of non-iconic ${ }^{3}$ signification in painting by Schapiro (1985) and Eco (1979) also acknowledge possibilities for translating from the verbal to the visual, although the examples given appear to stress the expressive limitations of this form of communication. Schapiro's example is the sizing of figures to signify social standing in certain artistic idioms, whilst Eco's is a horizontal line subtending a semicircle to signify a sunrise. Eco, however, regards such zones of translatability as limited. Beyond them there are, on the one hand, linguistic complexities which cannot be conveyed through systems of visual signification, and on the other, regions of unnameable entities wherein the meanings expressed through non-verbal media cannot, except to a weak approximation, be translated into verbal units.

The weight of opinion thus far is decidedly against the assumptions of translatability and molecularity. A major exception occurs in the work of Barthes and, in view of the standing of this author in the field of cultural studies, it is an exception which calls for discussion. For Barthes (1977, 1985), visual elements, communicate either by denotation or by connotation. Denotation is achieved simply through the recognition of the object represented. Connotation, on the other hand, draws on 'a plurality of culturally-determined lexica', for example, the signalling of 'Italianicity' in an advertisement for a food product by the presence of a tomato (1985). Although the connotations of a visual image can never be exactly reproduced in words, it is, nevertheless possible, in Barthes' view, to assemble complex meanings by juxtaposing images and manipulating the visual relationships between them (which may possess semiotic significance in their own right).

Insofar as this position endorses the assumptions of translatability and molecularity, it looks very encouraging for the management of product semiotics, until it is realised that Barthes' discussions are concerned exclusively with figurative representation. In effect, he both assumes and discounts the semiotics of visual representation in Langer's sense, discussing (for example) photographs as if they were the objects photographed. In this respect, Barthes' semiotics is that of the tableau vivant or the parlour game of charades.

It can be argued the figurative images used in advertising achieve their effect in exactly this fashion (Mick, 1986, McQuarrie and Mick, 1992; Mick, 1992), and it is perhaps significant that Barthes' examples of semiotics of the visual are taken from advertising rather than product design. Apart from such aesthetic masterworks as the pictorial T-shirt and the Toby Jug, however, little of product design is

\footnotetext{
${ }^{3}$ An icon, in the discourse of semiotics, signifies by some form of similitude rather than through the medium of a code. Eco (1987), however, argues that, in the limit, there is no such thing, since all notions of similarity depend on socially-sanctioned abstraction and are therefore coded.
} 
straightforwardly figurative. The semiotics of a motor car styling (for example) cannot begin by identifying the objects of which it is a representation.

As far as (most) product design is concerned, the apparent support for the assumptions of translatability and molecularity in the work of Barthes can be discounted. It follows that the weight of authority within interpretative semiotics is against these assumptions.

\subsection{Translatability and molecularity: the view from experimental aesthetics}

Methodologically speaking, Kawama's positivist procedure has far more in common with the tradition of experimental aesthetics than with interpretative semiotics. According to Holbrook (1987) experimental aesthetics can be traced back to Morris' (1964) behavioural approach to semiotics. We will now examine the extent to which this alternative tradition lends support the assumptions of translatability and molecularity.

The foundation of Morris' approach was a definition of the sign as something which produces a tendency to act. This linkage of semiotics to activity on the part of the beholder opened up the topic to empirical psychology. Morris' principle source on this field of study was Osgood et al (1957), for whom meaning could be apprehended only as an intermediary term in classical conditioning (as, for example, the bell, to Pavlov's dogs, 'meant' food). Osgood's instrument for the exploration of semiotics on these terms was the semantic differential questionnaire. Nowadays a commonplace of marketing research and practice, this requires subjects to describe their reactions to a sign in terms of a series of opposed descriptions (e.g. 'hot' and 'cold'). Each pair of opposites is connected by a seven-point scale, on which the subject is required to mark the 'distance' from each extreme of the sensations evoked by the sign. Morris explained how this device could advance our understanding of religion, philosophy and morality as well as aesthetics:

For example, a number of persons could rate on a seven-point scale how much they liked several paintings, poems, pieces of music, and so forth. . . . The use of modern statistical analysis (such as factor analysis) would permit empirical determination of which paintings "went with" (in terms of ratings) which poems, which music, which ways to live, which philosophies and which religions.

Morris, 1964 p. 73-74

In its reliance on the semantic differential questionnaire, this positivistic reduction of aesthetics to the scoring system of ice-dancing, is an obvious ancestor of Kawama's treatment of the visual sign as an approximation to a verbal message. Despite this common feature, however, the assumptions of translatability and molecularity underlying Kawama's experiment are missing.

Instead, the core assumption of 'the new experimental aesthetics' which developed from Morris' work (Berlyne et al, 1974) is that a work of art is something possessing 'positive hedonic value' (p. 8). This is to be assessed on semantic differential scales in which the opposites are such terms as ugly-beautiful, dislike-like and interestinguninteresting. Crucially, these words are descriptors of feeling-states, not words believed to evoke the same responses as visual signs. In this research, the 'hedonic response' is conceived of as a series of quantities which can be referred to by words 
(how beautiful, how interesting etc.), but not reproduced by them. There is, in other words, no assumption of translatability. Nor is there an assumption of molecularity. Although the work of art is to be 'analysed as an assemblage of elements' and 'a collection of symbols', there is also an explicit recognition of 'syntactical information' conveyed by the relationship between elements (Berlyn, 1974, pp. 6-7).

\subsection{The Pressure to be Useful: the Construction of a Managerial Semiotics}

It follows that neither the interpretative nor the positivist traditions of semiotic research support the assumptions of translatability and molecularity which underpin the attempt to adapt semiotics to the control of product design. This, it appears, is a version of semiotics heavily influenced by its purpose. As against this purpose, the weight of semiotic thinking emphasises the internal complexities and interdependencies of visual image, and its incommensurability with ordinary language. Both of these are qualities which tend to endorse the claim of design methodologists that the ability to design is 'a particular form of intelligence in its own right' (Cross, 1990), and one which cannot, in consequence, be second-guessed by those who lack it.

In the light of these dark currents flowing under the thin ice of his positivist methodology, Kawama's misgivings about the premises of his own research (page 8) are interesting. His doubts about the equivalence of words and elements of design, and his observations on the questionable stability of the relationships between the two, are symptomatic of an awareness of the subtleties of the relationship between design and accounts of design. That he nevertheless pressed ahead with the construction of his dictionary of translation is perhaps illustrative of the pressure to achieve practical results in management science. Either researchers convince themselves that phenomena are amenable to managerial intervention (as here) or there occurs a selection process involving grants, consultancies, and research access which favours those researchers who already believe this to be the case. Either way, something gets done, irrespective of whether or not it is possible to do anything.

\section{Managerial Semiotics as a Response to the Market for Systems of Accountability}

In this section of the paper, I would like to suggest that the attempt to enlist semiotics in the cause of design management is part of a broader response to the market for managerially amenable forms of accountability. The diffusion of the various forms of accounting-based management (narrowly defined), is another instance. Though the accounts in the case of the semiotic approach to design management are discursive rather than numerical, the common principle is still that management decisions are made on the basis of the accounts of activities given by those who carry them out. The various languages in which these accounts are given, moreover, have the common feature that they are intended to render the practices and outcomes of expertise intelligible to a managerial cadre which lacks this expertise. In this respect, these languages, and the various management sciences on which they are based appear as possible solutions to the agency problem posed by the 'task-discontinuous status organisation’ (Offe, 1976).

Task-continuous organisations are arranged as a hierarchy of positions in which essentially the same task is performed with increasing levels of expertise. In such 
organisations, the power of hierarchical position coincides with expert authority and the task of those in higher positions is to, advise, help and train those at lower levels. Professional organisations, such as accounting firms, are supposed to be examples of this (but see Hanlon, 1994 for a sensitive account of what actually happens). As the differentiation of specialised expertise increases, however, the task-continuous form of organisation becomes impractical. The task-discontinuous status organisation is characterised by abrupt changes in the kind of tasks carried out with ascending hierarchical position. Managers become experts not in performing the tasks which they manage, but in controlling them. Their power is no longer that of the expert, but that of the agent of capital or of political power - though that tends to be (mis)represented by management science as the power of the bureaucratic functionary or entrepreneurial 'fixer', depending on the fluidity or otherwise of the organisational structure.

Since it is premised on the control of expertise by those lacking it, the taskdiscontinuous organisation poses the problem of agency within the managerial hierarchy itself, a problem which creates an active market in management research whose agenda is precisely its solution. A familiar example from the field of accounting (narrowly defined) is the interdependent development of the multidivisional organisation and the systems of management accounting which enabled its dispersed expertise to be controlled from a single headquarters (Chandler, 1977; Williamson, 1975). Historically speaking, the task-discontinuity within this form of organisation was first bridged by the development of the R.O.I. measure of divisional performance (Sloane, 1986). In essence, such forms of accountability are simple languages within which operational managers are made to report their own activities. Inevitably, they are languages which distort, since they must discount the differences between the substantive forms of subordinate expertise and report its objectives and attainments in forms intelligible to the apparatus of headquarters decision-making and control. Similarly in the downwards direction, the strategies and plans decided upon at headquarters level are expressed primarily in the form of budgetary targets - or so runs the conceit of the management accountant (Anthony, Dearden, and Govindarajan, 1992). Management accounting, in other words, is a successful project within management science because it solves, or seems to solve, the agency problem inherent in the task-discontinuous status organisation. The downside, as has been extensively documented by critics of 'accounting by numbers' (e.g. Johnson and Kaplan, 1977), is that the translation of substantive activities into this language of accountability involves the neglect of aspects which are important even on the managerial scale of values (such as infrastructural investment) as well as others which are important to the public at large (such as environmental damage).

A further massive extension of the project of management accounting has occurred in the context of the world-wide displacement of collegiate by managerial forms of control in public sector services such as education, health and social services. The consequent diffusion of the task-discontinuous status organisation has posed problems of agency analogous to those of the multidivisional, and the response has been an 'audit explosion' in public sector services (Power, 1995) which has encouraged the development of novel non-financial indicators of performance as well as the adaptation of traditional financial measures. Here too, the paradoxes of what Humphrey, Miller and Scapens (1993) have called 'accountable management' have been extensively remarked. Inevitably, the translations of practice into indicators of 
practice inherent in this form of management entail simplifications and distortions which have encouraged self-defeating forms of gaming behaviour.

Although they are substantively very different, what these forms of accountability have in common with the semiotics project in design management is that they are attempts to solve the agency problem inherent in the task-discontinuous status organisation. By requiring the practitioners of an activity to report it in a language comprehensible to a stratum of general managers, it appears to become amenable to their powers of decision-making. The map, however, is not the terrain. To the extent that it misrepresents the nature of the activity being managed, action based upon it is likely to prove self-defeating. In the instance which has been described a major company has been led into a misguided attempt to convey complex textual messages to its customers through the medium of colour. At the same time, it is difficult to see how the task-discontinuous organisation could be managed other than through such systems of accountability. Even the much-touted alternative of trust-based 'clan control' (Ouchi, 1981) ultimately depends upon a culture sustained by exchanges of information, and these add up to 'horizontal' accountability in Roberts' sense (1991, 1996). The problem is not with systems of accountability as such, but with their adaptation to the task-discontinuous organisation. Possibly, this is a form or organisation within which managers have only a choice of costs: those of negotiating with expertise at arm's length - as has often been done with design consultancies (Bruce and Morris, 1994) - or those of a relative failure to control it on the basis of models which managers themselves find intelligible: the risks of artistic self indulgence versus the certainties of dullness.

\section{Implications for a Politics of Accountability}

Though this paper has now gone as far as the case of managerial semiotics will take it, it is unsatisfactory to conclude with a choice between collegiate control and managerial accountability. Too much discussion of accountability, in the public sector in particular, contents itself with elaborating its dysfunctions, as if it were obvious that unregulated practitioner control is preferable. I do not think that this is the case, nor that the two alternatives exhaust the possibilities.

In its celebration of the sensitivity of unregulated practitioner accountability, Oakes' paper (1996) raises the political issue in its sharpest form. Whatever the merits of enlisting practitioner expertise in the construction of accountability, it runs the risk of delivering the whole machinery into the hands of clan (Ouchi, 1981) or collegiate control. Whilst this does not add up to an abandonment of accountability, it is accountability in terms of a professional culture, rather than of that culture. If experts and professionals are to be held accountable only in terms defined by their own practice-based culture, this is functionally equivalent to professional ethics, with the sole difference that individual deviants might be dealt with by the authority to whom they are accountable rather than the profession itself. With this comparatively minor difference, it amounts to professional self-regulation, and the questionable consequences in the case of accountancy itself should, by now, need no elaboration (e.g. Humphrey, Moizer and Turley, 1992; Mitchell, Puxty, Sikka and Willmott, 1994; Sikka and Willmott, 1995; ). There needs to be a third way; one which enlists the expertise of the practitioner in the construction of a form of accountability, without yielding to its collective self-interest and without imposing the vocabularies and priorities of general management. A logical answer is to involve the public 
directly, and possible models for the construction of new forms of accountability along these lines have been developed in the field of architecture.

In architecture, the crisis for claims of a professional 'monopoly of competence' (Larson, 1977) was occasioned by a widespread public rejection of its most characteristic product - the windswept tower-block inspired by the romantic purism of Le Corbusier. This rejection precipitated the search for a rapprochement between professional expertise and public participation. One of the outcomes has been a conception of the participative design process as an hermeneutic exploration of the needs of the user (Coyne and Snodgrass, 1991, 1993). Designer and user are pictured, not as making their distinct contributions to the overall design process, but as engaged in a process of mutual learning in which architect and user come to understand each others' worlds. This process is conducted through the medium of trial designs and architectural models as much as through verbal discussion. There are clear convergences between this rethinking of architectural professionalism and Roberts' notion of horizontal accountability as dialogue $(1991,1996)$. What is added by the architectural model - and what could well be more widely applicable - is the notion that this dialogue needs to go beyond exchanges in ordinary language. For the practitioner, it involves the admission of the user into the practice itself, and for the user, in turn, this involves the responsibility to recognise the concrete constraints on the practice. It may be that this form of social exchange could form the model for the construction of forms of accountability which would both express the users' interest and remain sensitive to the nuances of expert practice. It might then be possible to stabilise the outcome of these hermeneutic explorations in a form analogous to the procedural agreement in industrial relations (Flanders, 1970), as an agreed discourse of accountability.

\section{References}

Anthony, R.N., Dearden, J. and Govindarajan, V., Management Control Systems. $7^{\text {th }}$ Edition. (Homewood, Ill: Irwin, 1992).

Armstrong, P. and Tomes, A., "Art and Accountability: the Languages of Design and Managerial Control”, Accounting, Auditing and Accountability Journal. Vol. 9, No. 5, 1996, pp 114-125.

Armstrong, P., (1991) "Contradictions and Social Dynamics in the Capitalist Agency Relationship”, Accounting Organisation and Society, Vol. 16, No 1, pp 1-25.

Barthes, R., "Rhetoric of the Image”, in Innis, R.E. (ed.) Semiotics: an Introductory Anthology, pp. 192-205 (Bloomington: Indiana University Press, 1985).

Barthes, R., “The Photographic Message”, in Barthes, R. Image, Music, Text: Essays Selected and Translated by Stephen Heath, pp. 15-31 (London: Flamingo, 1977).

Barthes, R., Mythologies, (Frogmore, St. Albans: Paladin, 1973).

Benveniste, É., “The Semiology of Language”, in Innis, R.E. (ed.) Semiotics: an Introductory Anthology, pp. 228-246 (Bloomington: Indiana University Press, 1985).

Berlyne, D.E. (ed) (1974) Studies in the new Experimental Aesthetics: Steps towards an objective psychology of aesthetic appreciation. Washington D.C. Hemisphere Publishing Co.

Berlyne, D.E. (1974) Verbal and Exploratory Responses to Visual Patterns Varying in Uncertainty and in Redundancy. Ch 5 pp. 121-158 in Berlyne, D.E. (ed) (op. cit.)

Boland, R.J. Jr. and Schultze, U. (1996) Narrating Accountability: cognition and the production of the accountable self. Ch. 4 in Munro, R and Mauritsen, J (Eds.) 
Accountability: Power, Ethos and the Technologies of Managing. London. International Thompson Publishing Inc. pp. 62-81.

Bruce, M. and Burrill, V., "Evaluation of the Communicative Effectiveness of Pack Design”, in Design Interfaces: Proceedings of the First Conference of the European Academy of Design: Volume 4. Design Management International Issues. Eco/ Environmental, Gender Issues., 1995, (Manchester: University of Salford 11th $-13^{\text {th }}$ April

Bruce, M. and Morris, B., "Managing External Design Professionals in the Product Development Process”, Technovation, Vol. 14, No. 9, 1994, pp. 585-599.

Chandler, A.D., The Visible Hand: the Managerial Revolution in American Business. (Cambridge Mass: Harvard University Press, 1977).

Channel 4 (UK Television) Auto-Erotic. Programme 1: The Sports Car. Programme 2: The Family Car, 1995

Chase (1993) The Chase by The Chase: How a Graphic Design Consultancy thinks it Thinks .Manchester. Cheetah Books.

Chua, W.F. and Preston, A., "Worrying about Accounting in Health Care", Accounting, Auditing and Accountability Journal, Vol. 7 No 3, 1994, pp. 4-17.

Cochrane, A., "From Financial Control to Strategic Management: the Changing Face of Accountability in British Local Government”, Accounting, Auditing and Accountability Journal, Vol. 6, No 3, 1993, pp 30-51.

Copps, A., "How Britons shape the world's wheels" The Times: Car '95 supplement, Saturday August 5, 1995,.

Coyne, R and Snodgrass, A “Co-operation And Individualism In Design”, Planning and Design, Vol. 20 No. 2, 1993, pp. 163-174.

Coyne, R. and Snodgrass, A., "Is designing mysterious? challenging the dual knowledge thesis”, Design Studies, Vol. 12 No 3, 1991, pp. 124-131.

Craig, A. and Hart, S., "Identifying Trends in the Literature: Determinants of NPD Success", Proceedings of the Marketing Education Group Conference. (Belfast: University of Ulster, 1994, pp. 211-229).

Cross, N., “The Nature and Nurture of Design Ability”, Design Studies, Vol. 11, No 3, 1990, pp. 127-140.

Eco. U., A Theory of Semiotics (Bloomington: Indiana University Press, 1979)

Ezzamel, M. and Willmott, H., "Corporate Governance and Financial Accountability: Recent Reforms in the UK Public Sector. Accounting, Auditing and Accountability Journal, Vol. 6, No 3, 1993, pp 109-132.

Flanders, A., Management and Unions: the theory and reform of industrial relations (London, Faber and Faber, 1970).

Gray, A. and Jenkins, W., "Codes of Accountability in the New Public Sector”, Accounting, Auditing and Accountability Journal, Vol. 6, No 3, 1993, pp 52-67.

Gray, R., Accounting for the Environment. (London: Paul Chapman, 1993).

Gray, R., Owen, D. and Adams, C., Accounting \& Accountability: Changes and Challenges in Corporate Social and Environmental Reporting. [2nd ed.]. (London: Prentice-Hall, 1996).

Gray, R., Owen, D. and Maunders, K., Corporate Social Reporting :Accounting and Accountability (London: Prentice-Hall, 1987).

Hanlon, G., The Commercialisation of Accountancy: Flexible Accumulation and the Transformation of the Service Class. (Basingstoke: St Martins Press, 1994). 
Holbrook, M.B. (1987) "The Study of Signs in Consumer Esthetics: an Egocentric Review.” in Umiker-Sebeok, D.J. (ed.) Marketing and Semiotics: New Directions in the Study of Signs for Sale. Berlin. Mouton de Gruyter. pp. 73-121.

Hoshino, K., “Semiotic Marketing and Product Conceptualisation”, in Umiker-Sebeok (ed.) Marketing and Semiotics: New Directions in the Study of Signs for Sale. pp. 41-55. (Berlin: Mouton de Gruyter, 1987).

Humphrey, C., Miller, P. and Scapens, R., "Accountability and Accountable Management in the UK Public Sector”, Accounting, Auditing and Accountability Journal, Vol. 6, No 3, 1993, p.p. 7-29.

Humphrey, C., Moizer, P. and Turley, S., “The Audit Expectations Gap”, Critical Perspectives in Accounting, Vol. 3, 1992, pp. 137-161.

Johnson, H.T. and Kaplan, R.S., Relevance Lost: the Rise and Fall of Management Accounting (Boston Massachusetts: Harvard Business School Press, 1987).

Johnson, H.T., Relevance Regained: from top-down control to bottom-up empowerment (New York: Free Press, 1992)

Kawama, T., “A Semiotic Approach to the Design Process”, in Umiker-Sebeok (ed.) Marketing and Semiotics: New Directions in the Study of Signs for Sale. pp. 5770. (Berlin. Mouton de Gruyter, 1987).

Langer, S.E., "Discursive and Presentational Forms” in Innis, R.E. ed. Semiotics: an Introductory Anthology, pp. 90-107, (Bloomington: Indiana University Press, 1985).

Larson, M.S., The Rise of Professionalism: a Sociological Analysis (Berkeley, University of California Press, 1977).

Laughlin, R., Broadbent, J. and Willing-Atherton, H., "Recent Financial and Administrative Changes in GP Practices in the UK: Initial Experiences and Effects”, Accounting, Auditing and Accountability Journal, Vol. 7 No 3, 1994, pp. 96-124.

Lawrence, S., Manzurul, A. and Lowe, A., “The Great Experiment: Financial Management Reform in the NZ Health Sector." Accounting, Auditing and Accountability Journal, Vol. 7 No 3, 1994, pp. 68-95.

Lorenz, C., The Design Dimension: the New Competitive Weapon for Business (Oxford: Blackwell, 1986).

McQarrie, E.F. and Mick, D.G., “On Resonance: a Critical Pluralistic Inquiry into Advertising Rhetoric”, Journal of Consumer Research, Vol. 19, 1992, pp. 180197.

Mick, D.G., "Consumer Research and Semiotics: Exploring the Morpohology of Signs, Symbols and Significance”, Journal of Consumer Research, Vol. 13, 1986, pp. 196-213.

Mick, D.G., "Levels of Subjective Comprehension in Advertising Processing and their Relations to Ad Perceptions, Attitudes and Memory" Journal of Consumer Research, Vol. 18, 1992, pp. 411-424.

Mitchell, A., Puxty, T., Sikka, P. and Willmott, H., "Ethical Statements as Smokescreens For Sectional Interests - the case of the UK accountancy profession”, Journal of Business Ethics, Vol.13, No. 1, 1994, pp. 39-51.

Moenaert, R., Deschoolmeester, D., Souder, W.E. and Demeyer, A., “InformationTransfer Between Research-And-Development And Marketing - Communication Frequency, Channel Selection, and Information-Content: an Evaluation”, Journal Of Scientific \& Industrial Research, Vol. 50, No. 10, 1991, pp. 727-737. 
Morris, Charles., Signification and Significance: a Study of the Relations of Signs and Values. (Cambridge Mass. M.I.T. Press, 1964)

Munro, R and Mauritsen, J (Eds.), Accountability: Power, Ethos and the Technologies of Managing. (London. International Thompson Publishing Inc., 1996)

Oakes, L. and Young, J., "Examining Notions of Accountability in Public and Private Spaces" (Critical Perspectives in Accounting Symposium, New York $26^{\text {th }}-27^{\text {th }}$ April 1996).

Offe, C., Industry and Inequality (London: Edward Arnold, 1976).

Ogden, S., "Transforming Frameworks of Accountability: the Case of Water Privatisation”, Accounting. Organisations and Society, Vol. 20 Nos. 2/3, 1995, pp. 193-218.

Osgood, C. E., Such, G, J. and Tannenbaum, P, H., The Measurement of Meaning. (Urbana, University of Illinois Press., 1957)

Ouchi, W. G., Theory Z: How American business can meet the Japanese challenge. (Reading Mass.: Addison-Wesley, 1981).

Owen, D. (ed.) Accountancy and the Challenge of the Nineties, (London: Chapman and Hall, 1992).

Power, M., The Audit Explosion, (London: Demos, 1995)

Roberts, J., "From Discipline to Dialogue: individualizing and socializing forms of accountability.” Ch. 3 in Munro, R and Mauritsen, J (Eds.) Accountability: Power, Ethos and the Technologies of Managing, pp. 40-61 (London. International Thompson Publishing Inc., 1996)

Roberts, J., "The Possibilities of Accountability.” Accounting, Organizations and Society. Vol. 10, No. 4, 1991, pp. 355-68.

Schapiro, M., "On Some Problems in the Semiotics of the Visual Arts: Field and Vehicle in Image-Signs”, in Innis, R.E. (ed.) Semiotics: an Introductory Anthology, pp. 208-225, (Bloomington. Indiana University Press, 1985).

Seymour Powell, R., Seymour Powell Publicity Brochure (Reprinted from Car Styling 70 and 89), (London: n.d.)

Sikka, P, Willmott, H., "The Power of Independence - defending and extending the jurisdiction of accounting in the United-Kingdom”, Accounting Organisations and Society, Vol. 20, No. 6, 1995, pp. 547-581.

Sloane, A.P., My Years with General Motors (Harmondsworth. Penguin, 1986).

Thompson, Chris., (Managing Director of Design Consultancy Fitch Richardson Smith), Talk on design of Electric Kettle for US Market, Design Council Research Workshop: Design Effectiveness, Tower Hotel, London, $7^{\text {th }}$ June 1995.

Umiker-Sebeok, D.J., "Preface.” in Umiker-Sebeok, D.J. (ed.) Marketing and Semiotics: New Directions in the Study of Signs for Sale. pp. ix-xii (Berlin. Mouton de Gruyter., 1987)

Williamson, O.E., Markets and Hierarchies: Analysis and Anti-trust Implications. (Englewood Cliffs, N.J.: Prentice-Hall, 1975). 